\title{
Le transporteur d'acides biliaires NTCP, un acteur majeur dans l'infection par les virus humains des hépatites offrant de nouvelles perspectives thérapeutiques
}

\author{
Eloi R. Verrier ${ }^{1}$ \\ Laura Heydmann ${ }^{1}$ \\ Thomas F. Baumert ${ }^{1,2}$ \\ Catherine Schuster ${ }^{1}$ \\ ${ }^{1}$ Université de Strasbourg, Inserm, \\ Institut de recherche sur les maladies \\ virales et hépatiques UMRS 1110 , \\ 67000 Strasbourg, France \\ $<$ e.verrier@unistra.fr> \\ 2 Institut hospitalo-universitaire, \\ Pôle hépato-digestif, \\ Nouvel hôpital civil, \\ 67000 Strasbourg, France
}

\begin{abstract}
Résumé. Les infections chroniques par les virus hépatiques sont un enjeu de santé publique mondiale. Les virus de l'hépatite B, C et D (VHB, VHC, VHD) sont les trois principaux virus responsables de ces affections graves du foie. Ils se caractérisent par des structures et des cycles viraux très différents mais sont liés par un hépatotropisme exclusif, suggérant l'existence de facteurs cellulaires hépatocytespécifiques impliqués dans ces infections. Si les cycles viraux sont relativement bien décrits, les interactions moléculaires entre virus et facteurs hépatiques sont encore en partie méconnues. Les facteurs de l'hôte impliqués dans ces infections virales constituent des candidats potentiels pour le développement de nouvelles cibles antivirales. Récemment, le transporteur d'acides biliaires pour sodium taurocholate co-transporting polypeptide (NTCP), exprimé majoritairement à la surface des hépatocytes, a été décrit comme le premier récepteur du VHB et du VHD. De plus, ce transporteur membranaire est impliqué dans la régulation de l'entrée du VHC, confirmant son importance lors de l'infection virale des hépatocytes. Le but de cette revue est de décrire les interactions entre NTCP et ces trois virus hépatotropes.
\end{abstract}

Mots clés : virus hépatiques, entrée virale, NTCP, acides biliaires

\begin{abstract}
Liver chronic infections by hepatotropic viruses remain a major health problem worldwide. Hepatitis B, C, and D viruses (HBV, HCV, HDV) are responsible for severe liver damages. In spite of different viral structures and life cycles, they all exclusively infect the liver, suggesting the presence of hepatocyte-specific factors allowing viral infection. If viral life cycles are already well described, the molecular interactions between liver host factors and viral structures remain elusive. Host factors represent promising targets for the development of new antiviral strategies. Recently, the bile acid transporter NTCP, mainly expressed at the cell surface of hepatocytes, was described as the first bona-fide receptor for both HBV and HDV. Moreover, this solute carrier was shown to be involved in the modulation of HCV entry, confirming its importance in liver infection by hepatic viruses. This review summarizes the interactions between NTCP and these three major viruses.
\end{abstract}

Key words: hepatotropic viruses, viral entry, NTCP, bile acids

\section{Introduction}

Les infections chroniques du foie par les virus de l'hépatite $\mathrm{B}$ et $\mathrm{C}$ (VHB et VHC) affectent plus de 500 millions de per-

Tirés à part : E.R. Verrier sonnes dans le monde, et représentent un problème majeur de santé publique [1,2]. Elles sont responsables de maladies hépatiques graves et évolutives, telles que la cirrhose et le carcinome hépatocellulaire $(\mathrm{CHC})$ qui constitue la seconde cause de mortalité par cancer dans le monde $[1,3,4]$. De plus, entre 5 et $10 \%$ des patients souffrant d'hépatite B chronique sont co-infectés par le virus de l'hépatite delta 
(VHD), un virus satellite du VHB qui détourne les protéines d'enveloppe du VHB pour assembler ses propres particules infectieuses [5]. Cette co-infection s'accompagne d'une aggravation de la maladie hépatique et d'une augmentation du risque d'apparition d'un CHC [5].

Un certain nombre d'avancées significatives dans le développement des traitements antiviraux a permis une amélioration notable de la prise en charge thérapeutique des patients. Ces traitements restent perfectibles et le développement de nouvelles stratégies de lutte antivirale demeure un enjeu majeur de la recherche médicale. En effet, en dépit de l'existence d'un vaccin préventif, la prévalence de l'infection par le VHB n'a que modérément décliné au cours des dernières années [3]. Les traitements actuels contre le VHB, basés sur l'utilisation d'interféron (IFN) pegylé de type I et d'analogues de nucléo(s)tides, limitent la réplication virale mais ne permettent pas la guérison des patients chroniquement infectés en raison de la persistance de l'ADN viral sous forme épisomale dans le noyau des cellules infectées [6, 7]. De même, dans le domaine de la recherche contre le VHC, les progrès considérables réalisés ces dernières années ont permis le développement de nouveaux agents antiviraux à action directe (Direct Acting Antivirals [DAAs]), permettant l'éradication du virus chez la plupart des patients [8]. Néanmoins, le coût très élevé de ces traitements limite leur accès à un nombre restreint de patients.

Parmi les nouvelles stratégies antivirales contre ces virus hépatotropes, les molécules ciblant les facteurs hépatiques (Myrcludex B, ITX 5061, Miravirsen, Alisporivir. . .) impliqués dans le cycle viral se révèlent prometteuses $[9,10]$. Elles pourraient en particulier permettre de limiter l'émergence de résistances virales lors des traitements par les DAAs, d'agir de manière pan-génotypique et de freiner la progression de la maladie hépatique en empêchant l'infection des hépatocytes néoformés [11]. L'entrée des virus dans les hépatocytes est la cible privilégiée de ces nouvelles stratégies, et les inhibiteurs d'entrée anti-VHC et anti-VHB/VHD ont d'ores et déjà montré leur efficacité pour non seulement prévenir, mais également guérir l'infection in vitro et in vivo [12-15]. Cette stratégie est encouragée par le succès de l'utilisation d'inhibiteurs de l'entrée virale au cours des thérapies antivirales contre le virus de l'immunodéficience humaine (VIH) [16]. L'identification de facteurs communs impliqués dans l'infection d'un organe par plusieurs virus permettrait le développement de stratégies antivirales à large spectre. Le tropisme exclusivement hépatique de VHB, VHD et VHC encourage la recherche de tels facteurs cellulaires impliqués dans l'entrée virale et spécifiques du foie.

Récemment, le transporteur d'acides biliaires sodium taurocholate co-transporting polypeptide (NTCP), très majoritairement exprimé à la surface des hépatocytes, a été identifié comme le premier récepteur commun au VHB et au VHD. Ce récepteur semble également jouer un rôle régulateur dans l'entrée du VHC. Le but de cette revue est de résumer les mécanismes moléculaires et cellulaires mis en jeu entre le transporteur NTCP et ces virus hépatotropes majeurs.

\section{Le polypeptide co-transporteur de Na/taurocholate (NTCP)}

Codé par le gène $S L C 10 A 1$, NTCP a été le premier membre décrit de la famille des « solute carriers » (SLC10) [17], qui comprend de nombreux transporteurs membranaires d'acides biliaires et de sodium. NTCP est une phosphoprotéine glycosylée de 349 acides aminés possédant neuf domaines transmembranaires, presque exclusivement exprimée à la surface basolatérale des hépatocytes $[18,19]$. Les substrats du NTCP sont principalement les acides biliaires couplés ou non à des sels, typiquement le taurocholate, dont il permet l'import dans les hépatocytes depuis la circulation systémique [17, 18] (figure 1). Quelques petites molécules comme la cyclosporine A (CsA), peptide cyclique aux propriétés immunosuppressives utilisé lors de transplantations d'organes, ou l'ezetimibe, utilisé dans le traitement de l'hypercholestérolémie, se fixent directement sur NTCP, inhibant l'entrée des acides biliaires dans les hépatocytes [20, 21].

La concentration en acides biliaires dans les hépatocytes est finement régulée en raison de leur forte cytotoxicité à concentration élevée. De ce fait, l'expression du NTCP dans les hépatocytes est régulée au niveau transcriptionnel par des hormones, des cytokines, mais également par les substrats eux-mêmes. Il est à noter que les lésions hépatiques peuvent affecter son expression [22]. En effet, les maladies hépatiques telles que la cirrhose biliaire primitive ou l'hépatite alcoolique choléstatique sont associées à une diminution de l'expression des pompes à acides biliaires tel que NTCP [23-25], avec pour conséquence une dérégulation de l'absorption et l'excrétion des acides biliaires. Au contraire, la surexpression du transporteur a été observée chez les patients souffrant de stéatohépatite nonalcoolique [26]. Récemment, Kang et al. ont montré que dans le CHC, la cycline D1 inhibe l'expression transcriptionnelle du NTCP en bloquant l'activité de son promoteur [27], ce qui pourrait expliquer l'absence d'expression de ce transporteur dans les lignées cellulaires dérivées de CHC, Huh7 et ses sous-clones, et HepG2. Sur le plan génétique, le polymorphisme de la séquence de SLC1OAl peut être associé à une modification d'expression de la protéine NTCP à la 


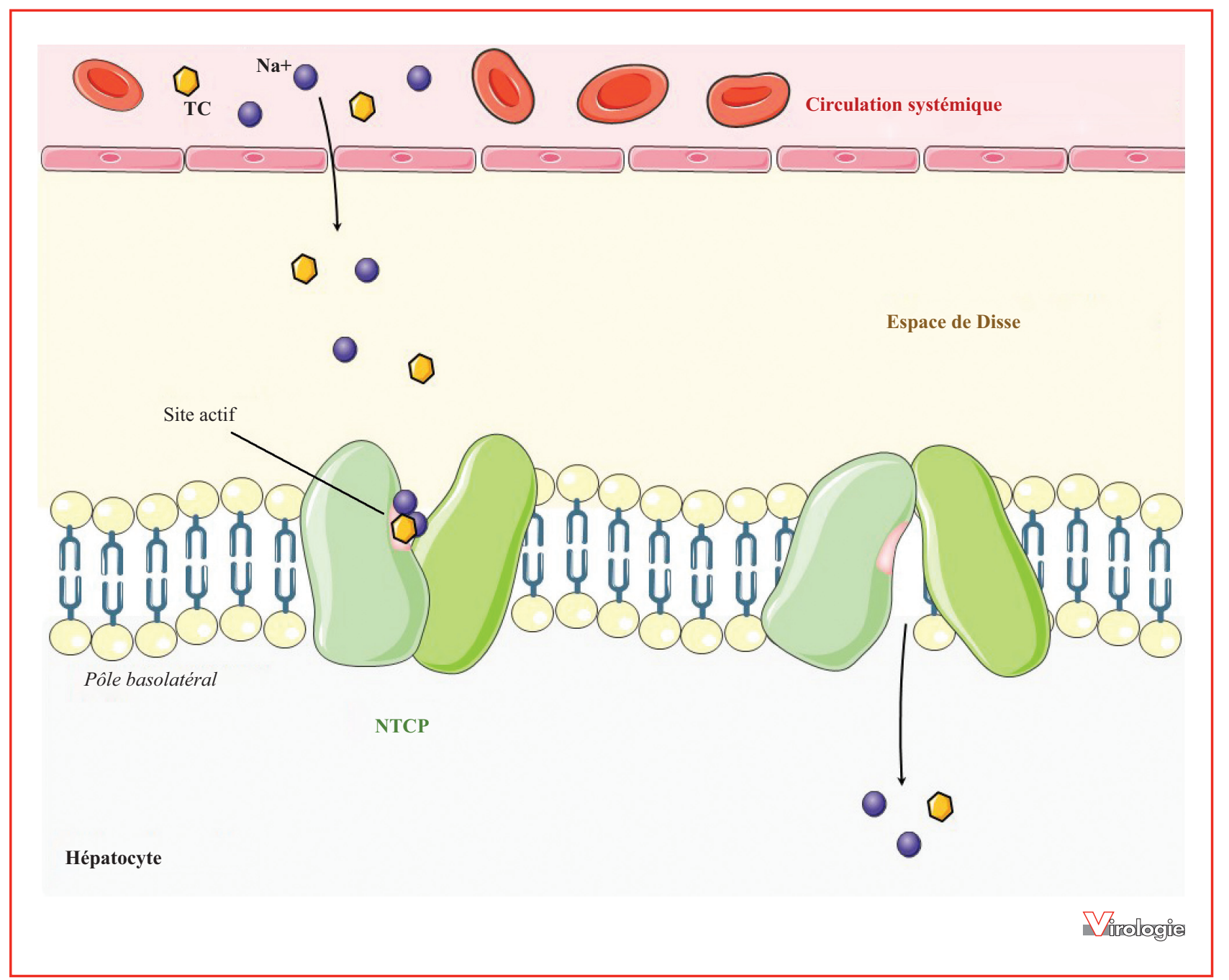

Figure 1. Import de taurocholate dans les hépatocytes médié par NTCP. Libérés dans l'espace de Disse depuis la circulation sanguine, les acides biliaires, et notamment le taurocholate (TC) sont importés dans les hépatocytes principalement via le transporteur NTCP (présenté ici de manière fonctionnelle) localisé au pôle basolatéral des cellules. Une molécule de taurocholate conjuguée à deux ions sodium ( $\mathrm{Na}+$ ) se lie au site actif du NTCP (ou « poche » d'acides biliaires). La liaison des ions $\mathrm{Na}+$ au transporteur induit un changement de conformation de la protéine qui se traduit par l'import des acides biliaires dans l'hépatocyte.

surface cellulaire, perturbant le transport des acides biliaires in vitro, mais la pertinence clinique de ces polymorphismes reste à déterminer [28].

En tant que transporteur membranaire, NTCP est exprimé à la membrane plasmique [18]. La régulation de l'expression membranaire du NTCP est également contrôlée par des mécanismes post-traductionnels [29]. Notamment, l'activation de la phosphatidylinisitol 3-kinase (PI3K) par l'AMP cyclique active les kinases $\mathrm{C}(\mathrm{PKC}) \zeta$ et $\delta$, qui à leur tour induisent la translocation du NTCP des endosomes vers la membrane plasmique en stimulant les GTPase Rab4 [30]. Au contraire, l'activation des PKC conventionnelles (cPKC), et notamment $\mathrm{nPKC} \alpha$, via le Tauroursodeoxycho- late par exemple, induit l'endocytose et l'internalisation du NTCP [29, 31]. Indispensable à l'homéostasie hépatique, NTCP joue également un rôle crucial dans l'infection par deux virus hépatiques majeurs, le VHB et le VHD.

NTCP est le récepteur fonctionnel du VHB et du VHD à la surface des hépatocytes.

\section{VHB et VHD : cycles infectieux}

Le VHB et le VHD sont deux virus très différents. Le VHD est un virus satellite du VHB qui requiert l'enveloppe du VHB pour accomplir l'ensemble de son cycle viral (figure 2). 


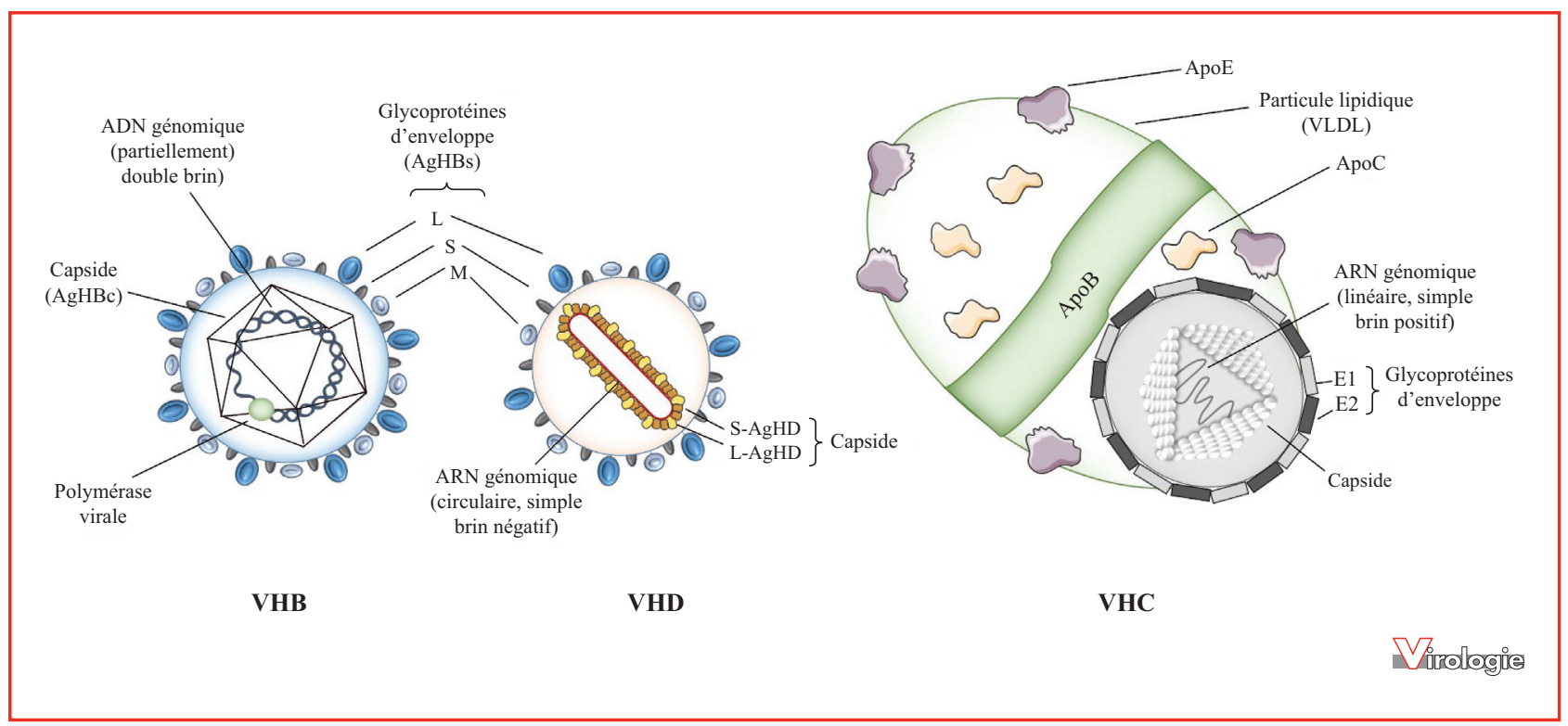

Figure 2. Structure des virus des hépatites B, C, et D (VHB, VHC, VHD). La particule virale du VHB, ou particule de Dane comporte une capside icosaédrique constituée de l'antigène core $(\mathrm{HBcAg})$, qui enferme le génome viral constitué d'un ADN circulaire partiellement double brin. Ce génome est lié à la polymérase virale, responsable de la retro-transcription au cours du cycle de réplication du VHB. L'enveloppe virale (AgHBs) est constituée des glycoprotéines virales S, M et L. Cette enveloppe est également utilisée par le VHD pour assembler ses particules infectieuses. Celles-ci sont composées, en plus des antigènes AgHBs, d'un génome sous forme d'ARN circulaire à simple brin négatif lié aux oligomères de capside, composés des deux formes de l'antigène delta (S-AgHD et L-AgHD). La particule virale du VHC est composée d'une capside formée par des multimères de la protéine core, qui enferme un génome sous forme d'ARN simple brin monocaténaire à polarité positive. Cette capside est enveloppée des glycoprotéines de surfaces E1 et E2. Dans le sang, la particule virale est liée à des particules lipidiques de type VLDL (very low density lipoproteines), comprenant notamment les apoliproprotéines ApoB, ApoC et ApoE.

Le VHB est un petit virus à ADN enveloppé hépatotrope, appartenant à la famille des Hepadnaviridae [32]. Les virions enveloppés et infectieux, aussi nommés particules de Dane, sont caractérisés par une nucléocapside icosaédrique, composée d' antigènes core $\mathrm{HBc}(\mathrm{AgHBc})$ et d'un génome viral circulaire relâché (rcADN) partiellement double brin de 3,2 kilo paires de bases (kpb), couplé à la polymérase virale $\mathrm{P}$ [33] (figure 2). L'enveloppe virale est constituée de trois antigènes de surface $(\mathrm{AgHBs})$ : la protéine $\mathrm{S}$ (pour small), la protéine $\mathrm{M}$ (pour middle) composée de $\mathrm{S}$ et d'une région preS2 et la protéine $\mathrm{L}$ (pour large) correspondant à l'assemblage de $\mathrm{S}$, preS2 et d'une région preS1 [33,34]. Les trois protéines d'enveloppe sont enchâssées dans une membrane lipidique d'origine cellulaire. Le cycle réplicatif du VHB est relativement bien décrit. Après l'entrée du virus dans les hépatocytes, la nucléocapside est libérée dans le cytoplasme et transportée dans le noyau [33-36]. La forme rcADN du génome viral est convertie par les protéines cellulaires en un ADN circulaire clos de façon covalente (ADNccc). L'ADNccc associé aux histones forme un minichromosome qui persiste dans le noyau et sert de matrice à tous les transcrits viraux dont l'ARN pré-génomique (ARNpg) [37]. Après export dans le cytoplasme, les ARN messagers (ARNm) viraux et
l'ARNpg, coiffés et polyadénylés, sont traduits en protéines structurales (core et AgHBs) et non-structurales (AgHBe, oncoprotéine $\mathrm{HBx}$ et ADN-polymérase ARN-dépendante $\mathrm{P})$. L'ARNpg se lie également à $\mathrm{P}$ et est encapsidé. Il est ensuite rétro-transcrit par $\mathrm{P}$ dans la nucléocapside en un nouvel ADN génomique [38]. Les particules virales néoformées sont ensuite exportées dans le milieu extracellulaire via la machinerie des corps multivésiculaires [39, 40]. Une proportion très importante de particules subvirales de $22 \mathrm{~nm}$ de diamètre constituées d'enveloppes virales vides est également produite [33].

Ces enveloppes virales seront nécessaires au VHD pour achever son cycle viral. Le VHD est un petit virus à ARN circulaire simple brin de 1,7 kpb de polarité négative codant pour une seule protéine structurale, l'antigène de capside delta, présent sous deux formes (longue L-AgHD et courte S-AgHD) [41] (figure 2). Les deux formes de l'antigène contribuent à la formation de la capside, et se lient à l'ARN génomique probablement sous la forme d'oligomères [41]. $\mathrm{S}-\mathrm{AgHD}$ stimule la réplication virale et est essentiel à l'accumulation d'ARN du VHD dans le noyau, alors que L-AgHD, qui inhibe l'activité de S-AgHD, est indispensable à la synthèse de nouveaux virions [41]. Pour assembler ses particules infectieuses, le virus utilise les protéines de 
surface AgHBs néoformées provenant de la réplication du $\mathrm{VHB}$, et ne peut donc répliquer complètement dans les hépatocytes que si ceux-ci sont préalablement infectés par le VHB [42]. Conséquence directe, les deux virus partagent les mêmes protéines d'enveloppe et le même mécanisme d'entrée dans les cellules hépatiques [43] (figure 2).

La réplication du VHD est également bien décrite. Après l'entrée dans la cellule, la ribonucléoprotéine est transportée dans le noyau, certainement via un signal de localisation nucléaire porté par L-AgHD [44]. La réplication virale implique l'activation des polymérases cellulaires, notamment l'ARN polymérase II, détournée de son activité initiale de transcription d'ADN en ARN $[45,46]$. L'ARN génomique de polarité négative sert de matrice à l'amplification par cercle roulant conduisant à la synthèse d'ARNm viral [47]. Les ARNm des AgHD sont traduits dans le cytoplasme et l'antigène delta est importé dans le noyau afin d'être associé au génome viral. En absence d'infection concomitante avec le VHB, le cycle viral s'arrête à cette étape et l'infection est avortée [48]. La ribonucléoparticule virale est ensuite exportée dans le cytoplasme où elle s'assemble au niveau du réticulum endoplasmique avec les protéines d'enveloppe du VHB, via la région C-terminale de L-AgHD [48]. La sécrétion des particules infectieuses néo-produites reste peu connue. Cependant, les voies de sécrétions des particules de Dane et des SVP du VHB semblant différentes [49], il est possible que les particules VHD soient sécrétées selon un mécanisme différent du VHB. Si les étapes des cycles viraux sont bien documentées, les interactions moléculaires entre ces virus et leur cellule hôte, l'hépatocyte, sont encore largement méconnues.

\section{La quête du récepteur}

Les premières étapes d'attachement des virus VHB et VHD à la surface des hépatocytes sont longtemps restées une zone d'ombre dans la compréhension du cycle infectieux. Notamment car les modèles cellulaires disponibles pour étudier l'infection par ces virus étaient peu nombreux et peu disponibles. Ils comprennent les hépatocytes primaires humains et les hépatocytes primaires du Toupaye de Belanger (Tupaia belangeri) (PHH et PTH, respectivement), ainsi que la lignée cellulaire humaine HepaRG, qui nécessite une différenciation d'une quinzaine de jours avant d'être sensible à l'infection virale (pour une revue, voir [50]). Malgré ces entraves, certaines étapes de l'entrée virale avaient pu être élucidées. En effet, depuis une dizaine d'années, on sait que l'entrée des virus débute par l'attachement des protéines d'enveloppe aux protéoglycanes à sulfate d'héparane ou HSPGs [51], et notamment Glypican 5 [52] (figure 3). De plus, la région $\mathrm{N}$-terminale myristoylée du domaine preS1 de la protéine d'enveloppe du VHB joue un rôle crucial dans l'infectivité du virus [53, 54]. Le lipopeptide soluble correspondant, identifié comme le site de liaison $\mathrm{du}$ virus au récepteur avant même l'identification de ce dernier, inhibe efficacement l'infection par le VHB et le VHD dans les hépatocytes [55-57] (figure 3). C'est en utilisant ce peptide preS1 myristoylé comme appât lors d'une étude protéomique sur des PTH que Yan et al. ont finalement identifié à la fin de l'année 2012 le premier récepteur fonctionnel du VHB et du VHD à la surface des hépatocytes, à savoir NTCP [58]. Cette découverte fut confirmée en parallèle par $\mathrm{Ni}$ et al., qui comparèrent le profil transcriptomique de cellules HepaRG différenciées et non différenciées, et identifièrent $S L C 10 A 1$ parmi les gènes induits par la différentiation [59]. Le rôle spécifique du NTCP dans l'entrée virale du VHB et du VHD a été confirmé par la surexpression du NTCP humain dans les lignées hépatocytaires classiques, Huh7 et HepG2, qui leur a conféré la sensibilité à l'infection par ces deux virus $[58,59]$. Il faut toutefois noter qu'une infection robuste dans ces lignées cellulaires nécessite une MOI très élevée (supérieure à 100 voire à 1000 dans de nombreuses études), ainsi que la présence de polyéthylène glycol et de DMSO. De ce fait, l'expression de NTCP seule est nécessaire mais peut-être pas suffisante pour assurer une entrée efficace, et suggère l'existence d'autres facteurs hépatiques impliqués dans ce processus. Quoiqu'il en soit, cette découverte a révolutionné la recherche sur le VHB et le VHD en offrant le premier modèle simple et efficace d'infection in vitro [60].

\section{Interaction entre $\mathrm{VHB} / \mathrm{VHD}$ et NTCP}

Le VHB et le VHD sont caractérisés par une spécificité d'espèce très stricte, infectant exclusivement l'homme, les chimpanzés et le Toupaye de Belanger, contrairement aux souris, rats, et singes non-primates [61]. Cependant, comme le génome du VHB est répliqué normalement in vitro dans les hépatocytes murins et simiens, la barrière d'espèce semble principalement se jouer à l'étape d'entrée virale, comme c'est le cas pour d'autres virus, ceux de la grippe, par exemple [62]. Rapidement, plusieurs études ont montré l'importance du NTCP dans la spécificité d'espèce de l'infection par ces deux virus. Notamment, la surexpression du transporteur NTCP murin ou celui du macaque crabier (Macaca fascicularis) dans les lignées cellulaires humaines n'a pas conféré la sensibilité à l'infection par le VHB et le VHD, à l'inverse du NTCP du Toupaye de Belanger [58, 63, 64]. À partir de constructions chimériques du NTCP humain et de macaque, la région des acides aminés 157 à 165 du NTCP humain a été identifiée comme cruciale pour la fixation du lipopeptide preS1 et pour l'infection par le VHB et le VHD, suggérant une interaction directe entre les protéines d'enveloppe du VHB 


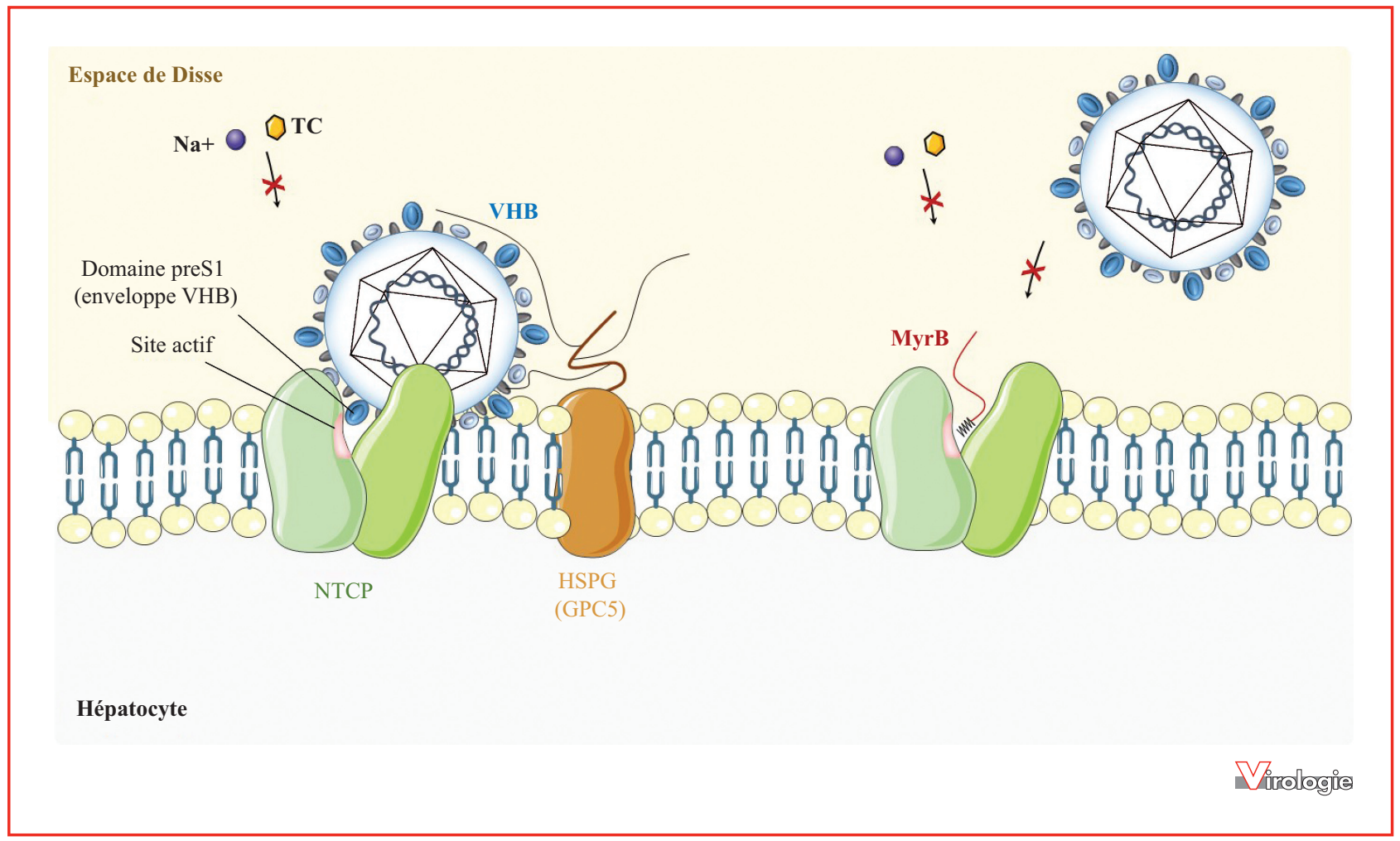

Figure 3. Interaction entre NTCP et le VHB. Depuis l'espace de Disse, le VHB s'attache tout d'abord à la membrane des hépatocytes via les protéoglycanes à sulfate d'héparane (HSPG), et notamment glypican 5 (GPC5). Le domaine preS1 des larges (L) protéines d'enveloppe interagit ensuite directement avec le récepteur au niveau de son site actif, ce qui se traduit par une inhibition de l'import des acides biliaires. Cette interaction induit l'internalisation de la particule virale selon un mécanisme encore inconnu. Le Myrcludex B (MyrB), lipopeptide preS1 myristoylé dérivé de l'enveloppe du VHB se lie spécifiquement au NTCP, inhibant le transport des acides biliaires et l'entrée du virus dans les hépatocytes.

et le NTCP [58]. Il est à noter que le site d'interaction NTCP-VHB concerne des résidus impliqués dans la fonction physiologique du transporteur. En effet, la fixation du lipopeptide preS1 et l'infection VHB elle-même perturbent le transport des acides biliaires, in vitro et in vivo [59, 65, 66] (figure 3). Réciproquement, les acides biliaires inhibent l'infection par le virus [59]. Par ailleurs, la mutation S267F du transporteur inhibe à la fois l'import d'acides biliaires et les infections par le VHB et le VHD in vitro [67]. Deux études génétiques chez les patients VHB ont de plus montré que l'allèle $\mathrm{S} 267 \mathrm{~F}$ du gène $S L C 10 \mathrm{Al}$ était associé à une résistance à l'infection chronique par le VHB, ainsi qu'à un risque moins élevé de développer une cirrhose ou un CHC [68, 69].

Les résidus responsables de l'interaction entre domaine preS1 et NTCP ne sont pas l'unique région du transporteur impliquée dans l'entrée du VHB. En effet, certains NTCP de mammifères-murin notamment-ont la capacité de fixer le lipopeptide preS1, alors même que ces animaux sont résistants à l'infection VHB, et que la surexpression de leur NTCP dans les lignées humaines ne confère pas la sensibi- lité aux infections VHB et VHD in vitro [59, 63]. Un autre domaine du récepteur (résidus $84-87$ ) joue un rôle clé dans l'entrée des virus induite par NTCP, sans que sa fonction soit à ce jour élucidée [63]. La substitution de trois acides aminés dans le NTCP de souris suffit à conférer la sensibilité à l'infection par le VHB dans les cellules HepG2 quand ce transporteur chimérique est surexprimé $[59,63]$.

NTCP est le premier récepteur identifié du VHB et du VHD. Les études récentes suggèrent qu'il est le facteur limitant de l'entrée de ces virus dans les hépatocytes, et est donc considéré comme une cible thérapeutique de premier choix pour le développement de nouvelles stratégies de traitement $[10,14,60]$.

\section{Récepteur du VHB et cible thérapeutique}

L'infection chronique par le VHB est caractérisée par la persistance du génome viral dans le noyau cellulaire sous la forme d'un minichromosome épisomal, l'ADNccc. Les traitements antiviraux actuels-basés sur l'administration d'IFN- $\alpha$ pegylé et d'analogues de nucléotides-permettent 
Tableau 1 Exemple d'inhibiteurs d'entrée du VHB ciblant NTCP.

\begin{tabular}{|llll|}
\hline Nom & Classe & Stade de développement & Références \\
\hline Myrcludex B & Peptide myristoylé & Essai clinique de phase II & {$[13]$} \\
\hline Cyclosporine A & Peptide non-ribosomal & $\begin{array}{l}\text { Modèles cellulaires (HepaRG-VHB ; Huh7-NTCP-VHD ; } \\
\text { HepG2-NTCP-VHB ; PHH-VHB) }\end{array}$ & {$[20,75]$} \\
\hline EGCG & Catéchine & Modèles cellulaires (HuS-E/2-VHB; Huh7-NTCP-VHB) & {$[79]$} \\
\hline Ezetimibe & B-lactam & Modèles cellulaires (HepaRG-VHB) & {$[76]$} \\
\hline Irbésartan & Sartan & Modèles cellulaires (Huh7-NTCP-VHD ; HepG2-NTCP VHB) & {$[77,78]$} \\
\hline Vanitaracin & Polycétide & Modèles cellulaires (HepG2-NTCP-VHB/VHD ; PHH-VHB) & {$[80]$} \\
\hline Ritonavir & Inhibiteur de protéase & Modèles cellulaires (Huh7-NTCP-VHD) & {$[77]$} \\
\hline
\end{tabular}

de réduire la virémie, mais la guérison totale n'est que très rarement observée [70]. De plus, ces traitements ne ciblent pas directement l'ADNccc qui peut se réactiver spontanément à tout moment. L'élimination de ce minichromosome viral reste un défi de taille qui nécessite soit sa déstabilisation, soit la destruction de l'hépatocyte infecté. À ce titre, plusieurs études préliminaires montrent des résultats encourageants sur la capacité d'inhiber la réplication du VHB en ciblant l'ADNccc à l'aide de la technologie CRISPR/Cas9, même si de nombreux défis liés notamment à la spécificité de la séquence ciblée et à l'efficacité de l'acheminement du guide vers la cellule cible infectée restent à résoudre [71]. En ce qui concerne le VHD, il n'existe à l'heure actuelle aucun traitement spécifique [72]. La recherche de nouvelles stratégies de traitement reste donc une priorité pour ces maladies chroniques. Dans ce contexte, bloquer l'entrée virale peut se révéler efficace. En effet, le système immunitaire, et notamment la réponse $\mathrm{T}$ cytotoxique, élimine progressivement les hépatocytes infectés au cours de l'infection. Les inhibiteurs d'entrée permettraient d'empêcher l'infection des hépatocytes néoformés lors du renouvellement cellulaire, et ainsi limiter la propagation de l'ADNccc [14]. Cette stratégie présente, de plus, l'avantage de cibler à la fois l'entrée du VHB et du VHD puisqu'ils partagent les mêmes mécanismes d'entrée dans les hépatocytes.

NTCP a été, à ce titre, très rapidement considéré comme une cible thérapeutique de choix (voir tableau 1). Il est à noter que la forme commerciale synthétique du lipopeptide preS1, le Myrcludex B, qui agit comme un leurre biologique se fixant spécifiquement au NTCP et inhibe l'infection par les deux virus, a déjà montré son efficacité préventive in vivo [56] (figure 3). Plus récemment, des études complémentaires ont démontré l'efficacité du Myrcludex $\mathrm{B}$ dans la prévention de la dissémination virale et la réinfection de nouveaux hépatocytes [73, 74], suggérant une utilisation potentielle de ce peptide pour le traitement des patients atteints d'hépatite $\mathrm{B}$ chronique. Une étude clinique de phase IIa a montré une bonne tolérance du Myrcludex
B, avec toutefois une efficacité modérée chez les patients (et ceci uniquement lorsqu'il est associé à l'IFN), la charge virale VHB n'étant diminuée que d'un ou deux log 10 maximum, sans effet significatif sur le taux d'AgHBs [13]. Utilisé en monothérapie, aucune activité antivirale significative n'a été observée. Le traitement semble beaucoup plus efficace pour réduire la charge virale VHD, jusqu'à devenir non-détectable chez deux patients [13]. Ces réductions de charges virales s'accompagnent d'une amélioration des paramètres hépatiques (ALT). Il est à noter que ces études ont été réalisées sur de petites cohortes de patients et nécessitent d'être confirmées et approfondies. Outre le Myrcludex B, d'autres molécules ciblant NTCP ont été testées pour leur capacité à bloquer l'entrée virale (tableau 1). Ainsi, la CsA et l'ezetimibe inhibent l'infection par le VHB et le VHD via leur interaction avec le récepteur [20, 65, 75, 76] (figure 4). Certains inhibiteurs du NTCP possédant une autorisation de mise sur le marché ont également démontré de bonnes activités antivirales in vitro, notamment l'irbesartan (un anti-hypertenseur) qui inhibe les infections VHB et VHD dans les modèles cellulaires impliquant NTCP [77, 78]. Récemment enfin, un polyphénol extrait du thé vert (Camellia sinensis) (EGCG) a été identifié lors d'un criblage de molécules phytochimiques comme un inhibiteur de l'infection par le VHB. Il semblerait que EGCG modifie la localisation et la stabilité du NTCP, inhibant ainsi l'entrée virale de manière indirecte [79].

Une des difficultés dans l'utilisation des inhibiteurs du NTCP chez les patients est le potentiel impact de ces molécules sur la fonction physiologique du transporteur [81]. En effet, si le Myrcludex B semble bien toléré chez les patients, le peptide affecte tout de même le transport des acides biliaires, entraînant des modifications transcriptomiques notables chez la souris [66], et son effet à long terme chez l'Homme n'est pas connu. De ce fait, le développement d'inhibiteurs d'entrée n'affectant pas le transport des acides biliaires permettrait de limiter les effets secondaires potentiels du traitement. Récemment, Shimura et al. ont 


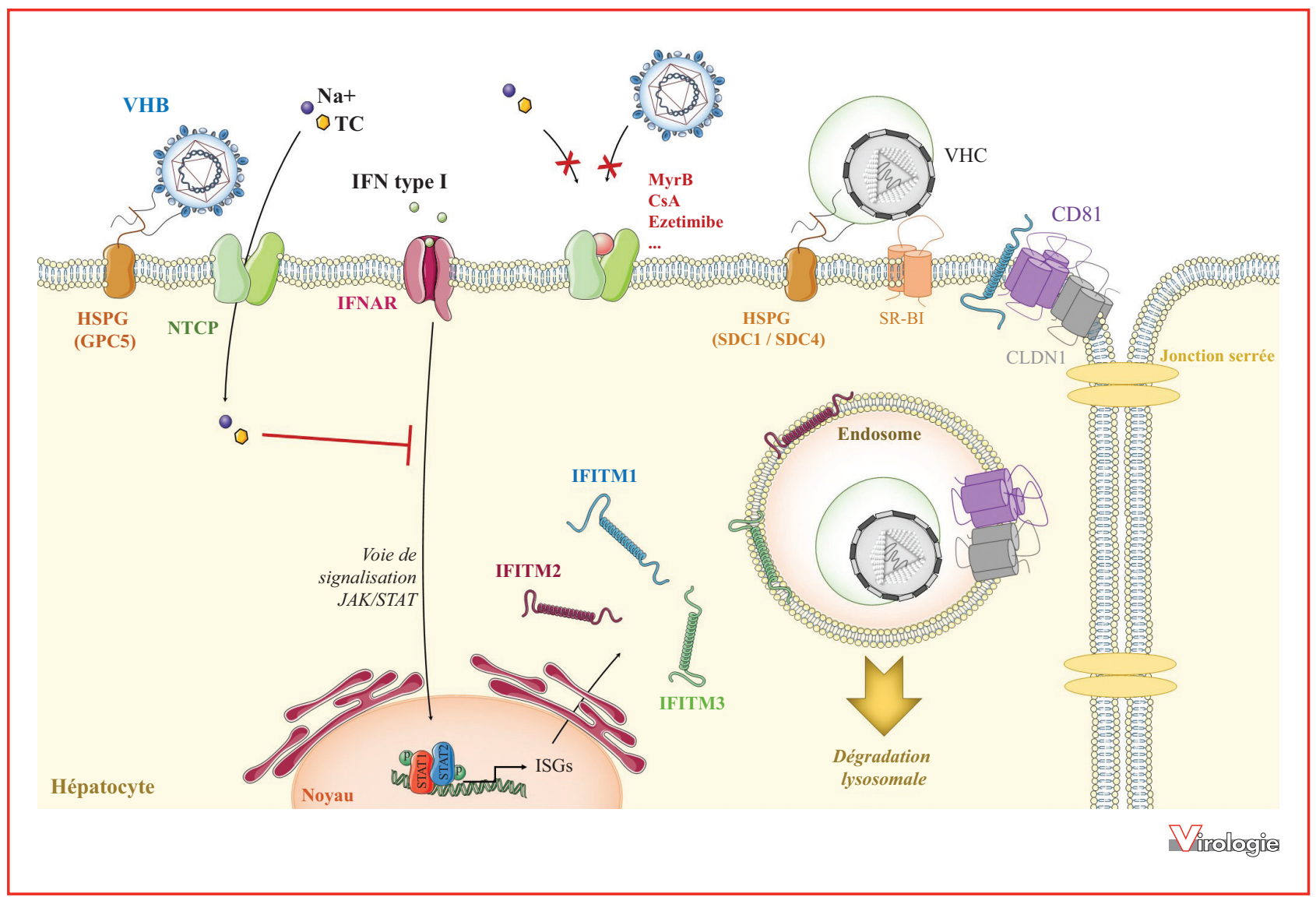

Figure 4. Rôle de NTCP dans l'entrée du VHB et du VHC. L'entrée du virus de l'hépatite B (VHB) dans les hépatocytes débute par l'attachement de la particule virale aux protéoglycanes à sulfate d'héparane (HSPG), et notamment glypican 5 (GPC5). Les protéines d'enveloppe du VHB interagissent ensuite directement avec le récepteur NTCP via le domaine preS1, avant l'internalisation de la particule virale selon un mécanisme encore inconnu. Cette interaction peut-être inhibée par le Myrcludex B (MyrB), lipopeptide preS1 dérivé de l'enveloppe du VHB, l'ezetimibe ou encore la cyclosporine A (CsA), qui inhibent également l'import des acides biliaires, et notamment le taurocholate $(\mathrm{Na}+/ \mathrm{TC})$. Ces acides biliaires ont la particularité d'inhiber la voie de signalisation JAK/STAT des interférons (IFN) de type I. Cette voie de signalisation conduit à l'import nucléaire du complexe phosphorylé STAT1/STAT2 qui stimule l'expression des gènes induits par l'IFN (ISG pour interferon stimulated genes), parmi lesquels IFITM1, IFITM2 et IFITM3. Ces gènes codent pour trois protéines transmembranaires connues pour inhiber l'entrée du virus de l'hépatite C (VHC) dans les hépatocytes. Celle-ci débute par l'attachement de la particule lipovirale aux HSPG, notamment syndecan 1 et 4 (SDC1, SDC4). La glycoprotéine virale E2 interagit ensuite avec le scavenger receptor class $B$ member 1 ou SR-BI qui transfère la particule virale à la tétraspanine CD81. IFITM1, qui peut se complexer à CD81, joue alors le rôle de perturbateur d'interaction avec le VHC. Au niveau des jonctions serrées, le complexe claudine 1 (CLDN1)-CD81 induit ensuite l'endocytose clathrine-dépendante du VHC. IFITM2 et IFITM3 sont exprimées à la membrane des endosomes, limitant sa fluidité et inhibant la libération de la particule virale dans le cytoplasme, qui sera alors dégradée par voie lysosomale.

identifié un dérivé de la CsA dépourvu à la fois d'activité immunosuppressive et d'inhibition de l'import des acides biliaires, mais présentant une activité antivirale marquée contre le VHB [82]. Même si le mécanisme d'action de cette molécule n'est pas encore élucidé, on peut imaginer que la modification de conformation de la molécule affecte soit l'encombrement induit par celle-ci, soit le domaine de fixation au récepteur, permettant ainsi toujours le passage des acides biliaires, mais empêchant la liaison du virus, bien plus volumineux [83]. Des analyses complémentaires sont nécessaires pour évaluer l'efficacité et la toxicité potentielle de cette molécule, toutefois, cette étude ouvre la porte à de nouvelles stratégies d'inhibition de l'entrée du VHB et du VHD.

La découverte du NTCP comme récepteur du VHB et VHD a révolutionné la recherche concernant ces virus et le traitement de leur infection. En fournissant les premiers modèles cellulaires simples d'études de l'infection par le VHB et VHD in vitro, elle a permis de mettre en place des criblages génétiques et chimiques afin d'identifier de nouveaux antiviraux ciblant toutes les étapes du cycle infectieux. Le transporteur lui-même a également été étudié comme 
cible antivirale, ouvrant la voie à des stratégies thérapeutiques innovantes. En tant que transporteur, exclusivement exprimé à la surface des hépatocytes, il est également un candidat de choix pour expliquer l'hépatotropisme des virus hépatiques, et la question de son implication dans l'entrée d'autres virus ciblant le foie a été récemment abordée.

\section{Acides biliaires, NTCP et entrée du VHC}

\section{Entrée du VHC dans les hépatocytes}

Le VHC est un virus à ARN simple brin positif, appartenant à la famille des flaviviridae. La nucléocapside, formée de la protéine structurale core multimérisée et du génome viral de 9,6 kpb, est enveloppée par une membrane d'origine cellulaire dans laquelle sont enchâssées les glycoprotéines de surface E1 et E2 nécessaires à l'entrée virale [84]. La forme infectieuse de la particule virale est associée à des particules lipidiques de type very low density lipoproteins (VLDL) [85] (figure 2). L'entrée virale est un processus complexe impliquant la liaison du virus à plusieurs co-récepteurs à la surface des hépatocytes [86] (figure 4). Comme pour le VHB, le cycle viral débute par l'attachement du virus aux HSPGs, notamment les syndecan 1 et 4 [87-89]. Cet attachement est probablement facilité par la liaison de E2 au récepteur des lipoprotéines à faible densité (low density liprotein ou rLDL) [90]. Le récepteur scavenger BI (SR-BI) interagit ensuite directement avec la lipoparticule virale et E2, [91] et transfère la particule à la tétraspanine CD81 [92]. L'interaction entre E2 et CD81 active une voix de signalisation via le récepteur du facteur de croissance épidermique (EGFR) [93], qui facilite alors la migration du complexe CD81-VHC vers les protéines de jonctions serrées [15]. La particule virale est internalisée via un complexe néo-formé entre CD81 et Claudin 1 (CLDN1) facilitant son endocytose clathrinedépendante [94]. Un certain nombre d'autres cofacteurs d'entrée au rôle encore incertain ont également été décrits, tels l'occludine (OCLN), le récepteur d'absorption du cholestérol Niemann-Pick C1 Like 1 (NPC1L1) ou le récepteur de la transferrine (TFRC) (pour une revue, [15]). Malgré les remarquables avancées de ces dernières années, l'hypothèse de l'existence de corécepteurs supplémentaires, notamment parmi les facteurs spécifiques des hépatocytes pouvant expliquer l'hépatotropisme du virus, reste toutefois posée.

\section{Interaction entre NTCP et VHC}

En tant que transporteur spécifique du foie, NTCP était un candidat idéal pour expliquer l'hépatotropisme des virus des hépatites tels le VHC. De plus, deux inhibiteurs connus du NTCP bloquent l'entrée du VHC, à savoir l'ezetimibe [95] et l'ECGC [96] (voir tableau 1), suggérant une interaction possible entre NTCP et le VHC. Plus récemment, une étude a montré que la surexpression du NTCP à la surface des cellules hépatocytaires Huh7.5.1 induisait une augmentation de l'entrée du VHC [97] alors que l'inhibiteur d'entrée du VHB, le Myrcludex B, limite également l'infection par le VHC. Cependant, les mécanismes d'interaction entre le VHC et NTCP semblent différents dans le cas du VHC car aucune liaison directe entre le virus et NTCP n'a été observée [97] à ce jour. En effet, c'est la fonction physiologique du transporteur qui est impliquée dans la régulation de l'entrée du VHC (figure 4). Il est connu depuis plusieurs années que les acides biliaires inhibent la voie de réponse des IFN de type I, expliquant du moins en partie l'absence de réponse efficace aux thérapies IFN chez les patients atteints de maladies hépatiques avancées [98, 99]. Ainsi, le blocage de l'import des acides biliaires dans la cellule par le Myrcludex B lève l'inhibition de la voie de réponse des IFN de type I, entraînant la surexpression d'un certain nombre d'ISGs (pour Interferon Stimulated Genes), dont IFITM1, IFITM2 et IFITM3 [97]. Ces gènes codent pour trois protéines transmembranaires impliquées dans l'inhibition de l'entrée de nombreux virus, tels les virus de la grippe et de la dengue [100]. Dans le cas du VHC, IFITM1 interagit avec CD81, perturbant l'interaction entre le virus et son récepteur [101], alors qu'IFITM2 et IFITM3 restreignent l'entrée virale après endocytose, en inhibant la libération de la particule virale dans le cytoplasme depuis l'endosome, celui-ci étant finalement dégradé par voie lysosomale [102] (figure 4). Ainsi, l'inhibition de l'import des acides biliaires via NTCP par le Myrcludex B stimule l'expression des ISGs, dont IFITMI, IFIMT2 et IFITM3, conduisant à une inhibition de l'entrée du VHC dans les cellules [97].

NTCP joue donc également un rôle de régulateur de la réponse antivirale innée dans les hépatocytes et cette fonction module l'entrée du VHC dans les cellules. Même si des investigations complémentaires sont nécessaires pour valider l'importance de ce mécanisme in vivo, cette observation ouvre des perspectives très intéressantes pour le traitement des patients co-infectés par le VHC, le VHB et le VHD, nombreux dans certaines populations à risque comme les utilisateurs de drogues injectables.

\section{Conclusion}

Les progrès significatifs accomplis ces dernières années pour mieux comprendre l'entrée des virus humains des hépatites dans leurs cellules cibles ont permis l'identification de nouveaux facteurs cellulaires impliqués dans l'interaction entre ces virus et les hépatocytes. NTCP est le premier facteur impliqué dans l'entrée de trois 
virus majeurs ciblant le foie. Sa découverte a permis en outre le développement de modèles d'étude in vitro qui permettent de récapituler l'intégralité du cycle infectieux du VHB. S'il ne permet que partiellement d'expliquer l'hépatotropisme de ces virus (pour le VHB et le VHD uniquement), il constitue une cible antivirale clé pour le développement de nouvelles stratégies de traitement. Dans le cadre d'infections chroniques du foie, caractérisées par une destruction des cellules infectées et un renouvellement des hépatocytes, les inhibiteurs d'entrée virale permettent d'empêcher la réinfection de nouvelles cellules, limitant ainsi la propagation du virus et la progression de la maladie hépatique, ainsi que l'émergence des résistances virales. Dans le cas particulier de greffes hépatiques, ces inhibiteurs pourraient permettre de limiter l'infection systématique du greffon. Dans l'optique d'un traitement contre le VHB et VHD, le Myrcludex B est déjà testé en essai clinique. Si une monothérapie efficace paraît utopique, l'association du Myrcludex B à d'autres antiviraux et/ou l'IFN pourrait à terme représenter une approche originale et efficace pour lutter contre ces deux virus majeurs. De plus, l'implication récemment décrite d'un rôle majeur du NTCP dans l'infection par le VHC et donc de trois virus très différents, mais ciblant le même organe, encourage la recherche de petites molécules ciblant le NTCP avec la perspective de développer un traitement universel pour VHB, VHC et VHD.

Remerciements. Les travaux de l'unité résumés dans cette revue ont notamment été financés par l'Agence nationale de la recherche sur le sida et les hépatites virales (ANRS, 15/1099).

Figures : certains éléments de figure ont été reproduits ou modifiés avec l'autorisation de Servier Medical Art (license : https://creativecommons.org/licenses/by/3.0/fr/).

Liens d'intérêts : les auteurs déclarent n'avoir aucun lien d'intérêt en rapport avec l'article.

\section{Références}

1. El-Serag HB. Epidemiology of viral hepatitis and hepatocellular carcinoma. Gastroenterology 2012;142:1264-73.

2. Wedemeyer H, Dore GJ, Ward JW. Estimates on HCV disease burden worldwide - filling the gaps. J Viral Hepat $2015 ; 22: 1-5$.

3. Trepo C, Chan HL, Lok A. Hepatitis B virus infection. Lancet $2014 ; 384: 2053-63$

4. Zeisel MB, Lucifora J, Mason WS, et al. Towards an HBV cure : stateof-the-art and unresolved questions-report of the ANRS workshop on HBV cure. Gut $2015 ; 64$ : 1314-26.

5. Wedemeyer H, Manns MP. Epidemiology, pathogenesis and management of hepatitis D : update and challenges ahead. Nat Rev Gastroenterol Hepatol $2010 ; 7: 31-40$
6. Trepo C, Chan HL, Lok A. Hepatitis B virus infection. Lancet $2014 ; 384: 2053-63$.

7. Habersetzer F, Moenne-Loccoz R, Meyer N, et al. Loss of hepatitis B surface antigen in a real-life clinical cohort of patients with chronic hepatitis B virus infection. Liver Int $2015 ; 35: 130-9$.

8. Chung RT, Baumert TF. Curing chronic hepatitis $\mathrm{C}-$ the arc of a medical triumph. N Engl J Med 2014 ; 370 : 1576-8.

9. Zeisel MB, Lupberger J, Fofana I, Baumert TF. Host-targeting agents for prevention and treatment of chronic hepatitis $\mathrm{C}$ - perspectives and challenges. J Hepatol 2013; 58 : 375-84.

10. Baumert TF, Verrier ER, Nassal M, Chung RT, Zeisel MB. Hosttargeting agents for treatment of hepatitis B virus infection. Curr Opin Virol $2015 ; 14: 41-6$.

11. Nathan C. Fresh approaches to anti-infective therapies. Sci Transl Med $2012 ; 4: 140$ sr2.

12. Mailly L, Xiao F, Lupberger J, et al. Clearance of persistent hepatitis C virus infection in humanized mice using a claudin-1-targeting monoclonal antibody. Nat Biotechnol $2015 ; 33$ : 549-54.

13. Bogomolov $\mathrm{P}$, Alexandrov A, Voronkova $\mathrm{N}$, et al. Treatment of chronic hepatitis D with the entry inhibitor myrcludex B : First results of a phase Ib/IIa study. J Hepatol 2016; 65 : 490-8.

14. Urban S, Bartenschlager R, Kubitz R, Zoulim F. Strategies to inhibit entry of HBV and HDV into hepatocytes. Gastroenterology $2014 ; 147: 48-64$.

15. Colpitts CC, Verrier ER, Baumert TF. Targeting viral entry for treatment of hepatitis B and C virus infections. ACS Infect Dis 2015; 1 :420-7.

16. Henrich TJ, Kuritzkes DR. HIV-1 entry inhibitors : recent development and clinical use. Curr Opin Virol 2013 ; 3:51-7.

17. Geyer J, Wilke T, Petzinger E. The solute carrier family SLC10 : more than a family of bile acid transporters regarding function and phylogenetic relationships. Naunyn Schmiedebergs Arch Pharmacol 2006; 372 : 413-31.

18. Claro da Silva T, Polli JE, Swaan PW. The solute carrier family 10 (SLC10) : beyond bile acid transport. Mol Aspects Med 2013; 34: 252-69. 19. Appelman MD, Chakraborty A, Protzer U, McKeating JA, van de Graaf SF. N-Glycosylation of the Na + -Taurocholate Cotransporting Polypeptide (NTCP) Determines Its Trafficking and Stability and Is Required for Hepatitis B Virus Infection. PLoS One 2017; 12 : e 0170419.

20. Nkongolo S, Ni Y, Lempp FA, et al. Cyclosporin A inhibits hepatitis $B$ and hepatitis $D$ virus entry by cyclophilin-independent interference with the NTCP receptor. J Hepatol $2014 ; 60: 723-31$.

21. Dong Z, Ekins S, Polli JE. Structure-activity relationship for FDA approved drugs as inhibitors of the human sodium taurocholate cotransporting polypeptide (NTCP). Mol Pharm 2013 ; 10: 1008-19.

22. Alrefai WA, Gill RK. Bile acid transporters : structure, function, regulation and pathophysiological implications. Pharm Res $2007 ; 24: 1803-23$.

23. Zollner G, Fickert P, Silbert D, et al. Adaptive changes in hepatobiliary transporter expression in primary biliary cirrhosis. $J$ Hepatol $2003 ; 38: 717-27$.

24. Zollner G, Fickert P, Zenz R, et al. Hepatobiliary transporter expression in percutaneous liver biopsies of patients with cholestatic liver diseases. Hepatology 2001; 33:633-46.

25. Kojima H, Nies AT, Konig J, et al. Changes in the expression and localization of hepatocellular transporters and radixin in primary biliary cirrhosis. J Hepatol 2003 ; 39 : 693-702.

26. Bechmann LP, Kocabayoglu P, Sowa JP, et al. Free fatty acids repress small heterodimer partner (SHP) activation and adiponectin counteracts bile acid-induced liver injury in superobese patients with nonalcoholic steatohepatitis. Hepatology $2013 ; 57: 1394-406$.

27. Kang J, Wang J, Cheng J, et al. Down-regulation of NTCP expression by cyclin D1 in hepatitis B virus-related hepatocellular carcinoma has clinical significance. Oncotarget 2017; $8: 56041-50$. 
28. Pan W, Song IS, Shin HJ, et al. Genetic polymorphisms in $\mathrm{Na}+$-taurocholate co-transporting polypeptide (NTCP) and ileal apical sodium-dependent bile acid transporter (ASBT) and ethnic comparisons of functional variants of NTCP among Asian populations. Xenobiotica $2011 ; 41: 501-10$.

29. Anwer MS. Role of protein kinase $\mathrm{C}$ isoforms in bile formation and cholestasis. Hepatology 2014 ; 60 : 1090-7.

30. Anwer MS. Cellular regulation of hepatic bile acid transport in health and cholestasis. Hepatology 2004 ; 39 : 581-90.

31. Stross C, Helmer A, Weissenberger K, et al. Protein kinase $\mathrm{C}$ induces endocytosis of the sodium taurocholate cotransporting polypeptide. Am J Physiol Gastrointest Liver Physiol 2010; 299 : G320-8

32. Zeisel MB, Lucifora J, Mason WS, et al. Towards an HBV cure : state-of-the-art and unresolved questions-report of the ANRS workshop on HBV cure. Gut 2015 ; 64 : 1314-26.

33. Seeger C, Mason WS. Molecular biology of hepatitis B virus infection. Virology 2015 ; 479-480 : 672-86.

34. Urban S. Liver capsule : Entry and entry inhibition of hepatitis B virus and hepatitis delta virus into hepatocytes. Hepatology 2016; $63: 633$.

35. Kann M, Schmitz A, Rabe B. Intracellular transport of hepatitis B virus. World J Gastroenterol 2007 ; 13 : 39-47.

36. Rabe B, Glebe D, Kann M. Lipid-mediated introduction of hepatitis $B$ virus capsids into nonsusceptible cells allows highly efficient replication and facilitates the study of early infection events. J Virol 2006; 80 : 5465-73.

37. Nassal M. HBV cccDNA : viral persistence reservoir and key obstacle for a cure of chronic hepatitis B. Gut 2015; 64 : 1972-84.

38. Jones SA, Clark DN, Cao F, Tavis JE, Hu J. Comparative analysis of hepatitis B virus polymerase sequences required for viral RNA binding, RNA packaging, and protein priming. J Virol 2014 ; 88 : 1564-72.

39. Dandri M, Locarnini S. New insight in the pathobiology of hepatitis B virus infection. Gut 2012;61 : 16-7.

40. Watanabe T, Sorensen EM, Naito A, Schott M, Kim S, Ahlquist P. Involvement of host cellular multivesicular body functions in hepatitis B virus budding. Proc Natl Acad Sci U S A 2007 ; 104 : 10205-10.

41. Taylor JM. Virology of hepatitis D virus. Semin Liver Dis 2012;32:195-200.

42. Rizzetto M, Hoyer B, Canese MG, Shih JW, Purcell RH, Gerin JL. delta Agent : association of delta antigen with hepatitis B surface antigen and RNA in serum of delta-infected chimpanzees. Proc Natl Acad Sci $U$ $S$ A $1980 ; 77: 6124-8$.

43. Sureau $C$. The use of hepatocytes to investigate HDV infection : the HDV/HepaRG model. Methods Mol Biol 2010; 640 : 463-73.

44. Chou HC, Hsieh TY, Sheu GT, Lai MM. Hepatitis delta antigen mediates the nuclear import of hepatitis delta virus RNA. J Virol $1998 ; 72: 3684-90$.

45. Chang J, Nie X, Chang HE, Han Z, Taylor J. Transcription of hepatitis delta virus RNA by RNA polymerase II. J Virol 2008;82: 1118-27.

46. Macnaughton TB, Shi ST, Modahl LE, Lai MM. Rolling circle replication of hepatitis delta virus RNA is carried out by two different cellular RNA polymerases. $J$ Virol $2002 ; 76: 3920-7$.

47. Flores R, Owens RA, Taylor J. Pathogenesis by subviral agents : viroids and hepatitis delta virus. Curr Opin Virol 2016; 17 : 87-94.

48. Sureau C, Negro F. The hepatitis delta virus : Replication and pathogenesis. J Hepatol 2016; 64 : S102-16.

49. Patient R, Hourioux C, Roingeard P. Morphogenesis of hepatitis $\mathrm{B}$ virus and its subviral envelope particles. Cell Microbiol 2009; 11 : 1561-70.

50. Verrier ER, Colpitts CC, Schuster C, Zeisel MB, Baumert TF. Cell Culture Models for the Investigation of Hepatitis B and D Virus Infection. Viruses 2016;8:261.
51. Schulze A, Gripon $P$, Urban $S$. Hepatitis $B$ virus infection initiates with a large surface protein-dependent binding to heparan sulfate proteoglycans. Hepatology 2007 ; 46 : 1759-68.

52. Verrier ER, Colpitts $\mathrm{CC}$, Bach $\mathrm{C}$, et al. A targeted functional RNA interference screen uncovers glypican 5 as an entry factor for hepatitis B and D viruses. Hepatology 2016; $63: 35-48$.

53. Gripon P, Le Seyec J, Rumin S, Guguen-Guillouzo C. Myristylation of the hepatitis B virus large surface protein is essential for viral infectivity. Virology $1995 ; 213$ : 292-9.

54. Blanchet M, Sureau C. Infectivity determinants of the hepatitis B virus pre-S domain are confined to the $\mathrm{N}$-terminal 75 amino acid residues. $J$ Virol $2007 ; 81: 5841-9$.

55. Engelke M, Mills K, Seitz S, et al. Characterization of a hepatitis B and hepatitis delta virus receptor binding site. Hepatology 2006; 43 : 750-60.

56. Petersen J, Dandri M, Mier W, et al. Prevention of hepatitis B virus infection in vivo by entry inhibitors derived from the large envelope protein. Nat Biotechnol $2008 ; 26: 335-41$.

57. Gripon P, Cannie I, Urban S. Efficient inhibition of hepatitis B virus infection by acylated peptides derived from the large viral surface protein. J Virol 2005 ; 79 : 1613-22.

58. Yan $\mathrm{H}$, Zhong G, Xu G, et al. Sodium taurocholate cotransporting polypeptide is a functional receptor for human hepatitis B and D virus. Elife 2012 ; 1 : e00049.

59. Ni Y, Lempp FA, Mehrle S, et al. Hepatitis B and D viruses exploit sodium taurocholate co-transporting polypeptide for species-specific entry into hepatocytes. Gastroenterology 2014 ; 146 : 1070-83.

60. Verrier ER, Colpitts CC, Sureau C, Baumert TF. Hepatitis B virus receptors and molecular drug targets. Hepatol Int 2016; 10: 567-73.

61. Li W, Urban S. Entry of hepatitis B and hepatitis D virus into hepatocytes : Basic insights and clinical implications. J Hepatol 2016; 64 : S32-40.

62. Kuiken T, Holmes EC, McCauley J, et al. Host species barriers to influenza virus infections. Science 2006 ; 312 : 394-7.

63. Yan H, Peng B, He W, et al. Molecular determinants of hepatitis B and $\mathrm{D}$ virus entry restriction in mouse sodium taurocholate cotransporting polypeptide. J Virol 2013; 87 : 7977-91.

64. Schieck A, Schulze A, Gahler C, et al. Hepatitis B virus hepatotropism is mediated by specific receptor recognition in the liver and not restricted to susceptible hosts. Hepatology $2013 ; 58: 43-53$.

65. Konig A, Doring B, Mohr C, et al. Kinetics of the bile acid transporter and hepatitis $\mathrm{B}$ virus receptor $\mathrm{Na}+/$ taurocholate cotransporting polypeptide (NTCP) in hepatocytes. J Hepatol 2014 ; 61 : 867-75.

66. Oehler N, Volz T, Bhadra OD, et al. Binding of hepatitis B virus to its cellular receptor alters the expression profile of genes of bile acid metabolism. Hepatology 2014; 60 : 1483-93.

67. Yan H, Peng B, Liu Y, et al. Viral entry of hepatitis B and D viruses and bile salts transportation share common molecular determinants on sodium taurocholate cotransporting polypeptide. J Virol 2014 ; 88 :3273-84.

68. Peng L, Zhao Q, Li Q, et al. The p.Ser267Phe variant in SLC10A1 is associated with resistance to chronic hepatitis B. Hepatology $2015 ; 61: 1251-60$.

69. Hu HH, Liu J, Lin YL, et al. The rs2296651 (S267F) variant on NTCP (SLC10A1) is inversely associated with chronic hepatitis B and progression to cirrhosis and hepatocellular carcinoma in patients with chronic hepatitis B. Gut 2016; 65 : 1514-21.

70. Werle-Lapostolle B, Bowden S, Locarnini S, et al. Persistence of cccDNA during the natural history of chronic hepatitis $\mathrm{B}$ and decline during adefovir dipivoxil therapy. Gastroenterology 2004 ; 126 : 1750-8.

71. Moyo B, Bloom K, Scott T, Ely A, Arbuthnot P. Advances with using CRISPR/Cas-mediated gene editing to treat infections with hepatitis B virus and hepatitis C virus. Virus Res 2017, pii: S0168-1702(16)30733-X. doi: 10.1016/j.virusres.2017.01.003. [EAP]. 
72. Farci P, Mandas A, Coiana A, et al. Treatment of chronic hepatitis D with interferon alfa-2a. $N$ Engl J Med 1994 ; 330 : 88-94.

73. Lutgehetmann M, Mancke LV, Volz T, et al. Humanized chimeric uPA mouse model for the study of hepatitis $\mathrm{B}$ and $\mathrm{D}$ virus interactions and preclinical drug evaluation. Hepatology 2012; 55 : 685-94.

74. Volz T, Allweiss L, Ben MM, et al. The entry inhibitor Myrcludex$\mathrm{B}$ efficiently blocks intrahepatic virus spreading in humanized mice previously infected with hepatitis B virus. J Hepatol 2013;58: 861-7.

75. Watashi K, Sluder A, Daito T, et al. Cyclosporin A and its analogs inhibit hepatitis B virus entry into cultured hepatocytes through targeting a membrane transporter, sodium taurocholate cotransporting polypeptide (NTCP). Hepatology 2014; 59: 1726-37.

76. Lucifora J, Esser K, Protzer U. Ezetimibe blocks hepatitis B virus infection after virus uptake into hepatocytes. Antiviral Res 2013;97: 195-7.

77. Blanchet M, Sureau C, Labonte P. Use of FDA approved therapeutics with hNTCP metabolic inhibitory properties to impair the HDV lifecycle. Antiviral Res 2014; 106 : 111-5.

78. Ko C, Park WJ, Park S, et al. The FDA approved drug irbesartan inhibits HBV-infection in HepG2 cells stably expressing sodium taurocholate co-transporting polypeptide. Antivir Ther $2015 ; 20: 835-42$.

79. Huang HC, Tao MH, Hung TM, Chen JC, Lin ZJ, Huang C. (-)-Epigallocatechin-3-gallate inhibits entry of hepatitis B virus into hepatocytes. Antiviral Res 2014; $111: 100-11$.

80. Kaneko M, Watashi K, Kamisuki S, et al. A Novel Tricyclic Polyketide, Vanitaracin A Specifically Inhibits the Entry of Hepatitis B and D Viruses by Targeting Sodium Taurocholate Cotransporting Polypeptide. J Virol $2015 ; 89: 11945-53$.

81. Slijepcevic D, van de Graaf SF. Bile Acid Uptake Transporters as Targets for Therapy. Dig Dis $2017 ; 35: 251-8$.

82. Shimura S, Watashi K, Fukano K, et al. Cyclosporin derivatives inhibit hepatitis B virus entry without interfering with NTCP transporter activity. J Hepatol 2017; 66 : 685-92.

83. Verrier ER, Schuster C, Baumert TF. Advancing hepatitis B virus entry inhibitors. J Hepatol 2017; 66 : 677-9.

84. Bartenschlager R, Penin F, Lohmann V, Andre P. Assembly of infectious hepatitis C virus particles. Trends Microbiol 2011; 19:95-103.

85. Crouchet E, Baumert TF, Schuster C. Hepatitis C virus-apolipoprotein interactions : molecular mechanisms and clinical impact. Expert Rev Proteomics 2017; $14: 593-606$.

86. Baumert TF, Meredith L, Ni Y, et al. Entry of hepatitis B and C viruses - recent progress and future impact. Curr Opin Virol 2014;4C : 58-65.
87. Barth H, Schafer C, Adah MI, et al. Cellular binding of hepatitis C virus envelope glycoprotein $\mathrm{E} 2$ requires cell surface heparan sulfate. $\mathrm{J} \mathrm{Biol}$ Chem $2003 ; 278: 41003-12$.

88. Lefevre M, Felmlee DJ, Parnot M, Baumert TF, Schuster C. Syndecan 4 is involved in mediating HCV entry through interaction with lipoviral particle-associated apolipoprotein E. PLoS One 2014; 9 : e95550.

89. Shi Q, Jiang J, Luo G. Syndecan-1 serves as the major receptor for attachment of hepatitis $\mathrm{C}$ virus to the surfaces of hepatocytes. $J$ Virol $2013 ; 87: 6866-75$.

90. Owen DM, Huang H, Ye J, Gale Jr. M. Apolipoprotein E on hepatitis C virion facilitates infection through interaction with low-density lipoprotein receptor. Virology 2009; 394 : 99-108.

91. Zeisel MB, Koutsoudakis G, Schnober EK, et al. Scavenger receptor class $\mathrm{B}$ type $\mathrm{I}$ is a key host factor for hepatitis $\mathrm{C}$ virus infection required for an entry step closely linked to CD81. Hepatology 2007; 46 : 1722-31. 92. Pileri $\mathrm{P}$, Uematsu $\mathrm{Y}$, Campagnoli S, et al. Binding of hepatitis $\mathrm{C}$ virus to CD81. Science $1998 ; 282$ : $938-41$.

93. Lupberger J, Zeisel MB, Xiao F, et al. EGFR and EphA2 are host factors for hepatitis $\mathrm{C}$ virus entry and possible targets for antiviral therapy. Nat Med 2011; $17: 589-95$.

94. Farquhar MJ, Hu K, Harris $\mathrm{HJ}$, et al. Hepatitis $\mathrm{C}$ virus induces CD81 and claudin-1 endocytosis. J Virol 2012;86:4305-16.

95. Sainz Jr. B, Barretto N, Martin DN, et al. Identification of the NiemannPick C1-like 1 cholesterol absorption receptor as a new hepatitis $\mathrm{C}$ virus entry factor. Nat Med 2012; $18: 281-5$.

96. Colpitts CC, Schang LM. A small molecule inhibits virion attachment to heparan sulfate- or sialic acid-containing glycans. J Virol $2014 ; 88: 7806-17$.

97. Verrier ER, Colpitts CC, Bach C, et al. Solute Carrier NTCP Regulates Innate Antiviral Immune Responses Targeting Hepatitis C Virus Infection of Hepatocytes. Cell Rep 2016; 17 : 1357-68.

98. Podevin $\mathrm{P}$, Rosmorduc $\mathrm{O}$, Conti $\mathrm{F}$, et al. Bile acids modulate the interferon signalling pathway. Hepatology 1999;29:1840-7.

99. Graf D, Haselow K, Munks I, Bode JG, Haussinger D. Inhibition of interferon-alpha-induced signaling by hyperosmolarity and hydrophobic bile acids. Biol Chem 2010;391:1175-87.

100. Smith S, Weston S, Kellam P, Marsh M. IFITM proteins-cellular inhibitors of viral entry. Curr Opin Virol 2014; 4:71-7.

101. Wilkins C, Woodward J, Lau DT, et al. IFITM1 is a tight junction protein that inhibits hepatitis C virus entry. Hepatology 2013; 57:461-9. 102. Narayana SK, Helbig KJ, McCartney EM, et al. The Interferoninduced Transmembrane Proteins, IFITM1, IFITM2, and IFITM3 Inhibit Hepatitis C Virus Entry. J Biol Chem 2015 ; 290 : 25946-59. 